\title{
THE APPROACH TO REgIONAL PLANNING IN NATAL
}

\section{Introduction:}

Limitations on the development of regional planning in the Republic are no longer due to lack of public interest or the availability of funds, but rather to a tragic shortage of men and women trained to undertake the work. While being conscious and most appreciative of the great honour and kindness extended to me by the University of Potchefstroom in inviting me to address so distinguished a company today, may I also say what a great pleasure it is to be present at the inauguration of an Institute for Regional Planning which will have as one of its main objects, the training of regional planners to help meet South Africa's needs.

Regional Planning in undeveloped regions comprises the study of all the resources of the area - existing and potential - with a vieu to the preparation of a plan for their balanced exploitation. In metropolitan regions the emphasis is rather different, since the problem lies not so much in the stimulation of latent potential, but rather in the guiding of a dynamic growth which is already operating, into a pattern which will be conductive to the greatest efficiency in production and the greatest pleasantness and convenience for all the dwellers in the metropolis.

In both cases the regional plan must fit into the national frame work and must be viewed in perspective against national needs and national policies. The setting up of a Central Government Department to deal, inter alia, with physical planning is therefore of great significance to the conduct of purely regional planning - for two reasons. Regional planning authorities are able to feed information on the potentialities of regions which they have studied, into the Department of Planning. This information can assist the Department to form a picture of national potentialities and formulate a national development programme with a system of prioriteis, which can then be fed back to the regions.

The proper functioning of planning at regional level is dependent on the existence of an active national planning authority, and consequently the creation of the Department of Planning was a cause for the greatest satisfaction to those of us who have been concerned with regional planning in Nata!. 
The Honourable the Minister of Planning has sometimes referred to the organisation of physical planning in South Africa as a Three-Tier-System, with the Government as the top tier, the Provincial Administrations as the middle tier, and the local authorities as the lower tier. Regional Planning in Natal has been conducted by an arm of the Provincial Administration, and my description of the activities which have been conducted therefore represents the viewpoint from the middle tier of government.

Those who provided the early inspiration for the work of the Tennessee Valley Authority stressed the importance of the activities of the Authority being rooted in the people of the region, so that local knowledge, and local loyalties could be harnessed to participate in the project so that the local people could feel the plan was their plan and not one foisted on them from above. The Provincial Administration through its intimate personal connection not only with local authorities but also other organised bodies and their members throughout the Province, is favourably placed to secure the co-operation of those working at the grass roots. The Provincial Administration also has a more mundane but nevertheless fundamental virtue, and that is the ability to vote funds for the payment of its own staff and also for the support of reseach workers and specialist consultants. Whatever has been achieved in Natal in the field of regional planning is, therefore, attributable, in the first place, to the initiative and support of the Natal Provincial Administration.

Regional development does not comprise a series of virtually water-tight compartments - agriculture - mining industry - communications - towns and so forth, but rather one process with many facets. Regional planning therefore presupposes not merely that the planning unit is large enough to be termed a region but also that the planning approach is broad enough to envisage development in its entirety. In this process if we are to find solutions to our problems which will stand the test of time, there is a necessity for institutions where the facts can be patiently assembled and analysed by scientific method. Already important work of this sort has been conducted within the Universities and of course at the C.S.I.R. So far, in the main, the work accomplished has comprised specialised investigations on specific aspects of regional planning, but the creation of an Institute of Regional 
Planning opens up the wider prospect of engaging in basic thinking upon fundamental problems of regional planning as such, a task which can only be done inadequately by those in official positions who are burdened with a host of statutory and day to day duties.

Although of recent years there has been unprecedented interest in the under-developed countries of the world, there is a surprising lack of literature on the regional planning of such territories. When therefore sixteen years or so ago a start was made on regional planning in Natal, it was necessary to evolve a technology suited to the planning of a vast undeveloped region in South African conditions. This paper will describe the methods which have been used.

\section{The town and regional planning commission}

In 1943 the Executive Committee appointed a Post-War Works and Reconstruction under the chairmanship of Mr D. E. Mitchell, who at that time was a member of the Executive Committee of the Province. In conformity with the recommendations of this Commission, a Provincial Town and Regional Planner was appointed in 1947 and the Town and Regional Planning Commission was created in 1951.

The nine members of the Town and Regional Planning Commission are appointed by the Administrator-in-Executive Committee as being "representative of the public life of Natal" and include figures prominent in organised commerce, industry, agriculture and local government, as well as others intimately associated with the development of land, buildings and roads. The Commission is sustained by funds voted annually by the Provincial Council, and its staff are members of the Public Service. The Provincial Town and Regional Planner (now re-designated Director, Town and Regional Planning) acts as technical adviser to the Commission.

As its name implies, the Commission exercises functions in the field of town planning as well as regional planning, but this paper is confined to consideration of the latter function.

The Commission has concentrated its regional planning activities in the Tugela Basin $(11,200$ square miles) and the Three Rivers Region (i.e. the catchments of the Umvoti, Umgeni and Illovo Rivers - 4,350 square miles in extent). Within this latter region special priority has been given to the Pieter- 
maritzburg—Durban Complex (2,900 square miles).

\section{Tugela Basin}

The Provincial Administration was asked by the Natural Resources Development Council in 1949 to give priority in its planning programme to a study of the Tugela Basin, which comprises one third of the Province. This request arose out of the view held by many responsible authorities that the Vaal River on which the principal industrial complex of the country depended, would within a measurable time be unable to meet the increased demands being made upon its resourches. The need for a new industrial complex in a well-watered area of South Africa, was therefore foreseen, and the Tugela Basin was thought to be well placed for that purpose. It has been estimated that its rivers could support six cities the size of Johannesburg, six the size of Cape Toun, four the size of Durban and four the size of Pretoria and still leave sufficient flow at Tugela Mouth to support a metropolis the size of Greater London. In addition to these great water resources, its central position midway between the port of Durban and the goldfields of the Witwatersrand and the Orange Free State; its Bantu population of half a million persons and its coalfield, fit the region for large-scale industrial development.

The purpose of the investigation was to determine the resources and potentialities of the area and then to plan its comprehensive development.

In 1952 the Commission's staff completed a regional survey which comprised for the most part a résumé of available information on the Basin, culled from published and unpublished works, augmented by information obtained from interviews with government officials, industrial and mining executives, farmers, etc. $\left.{ }^{1}\right)$ This report revealed significant gaps in available knowledge, which the Commission determined to make good by a comprehensive programme of regional research, partly undertaken by the staff and partly by specialised studies at research institutions.

The staff embarked upon a study of the physical characteristics of the region and its suitability for industrial and other development but, in addition, a series of research fellowships was sponsored by the Commission at various faculties of the University of Natal and with the South African Council 
for Scientific and Industrial Research (C.S.I.R.). The usual arrangement has been for a contract to be entered into whereby for an agreed annual sum the research organisation has provided a properly qualified graduate research fellow to conduct the required research, experienced technical supervision usually by the professor of the appropriate faculty, accommodation (including laboratory facilities and scientific equipment), means of transport and incidental expenses. Each fellowship is directed by a Steering Committee composed of leading experts in the particular field of research on the one hand, and representatives of the Commission whose duty it is to ensure that the research follows the direction required for planning purposes, on the other.

\section{Agriculture}

The practices of agriculture can fundamentally affect the life of storage dams upon which future development will depend. Furthermore, where large-scale urbanization is expected, it is important to remember that a concentrated urban market carries with it the temptation to exploit the soil beyond its long-term potential. It is therefore of the greatest importance for the true agricultural potential of the immediately contiguous region to be determined as early as possible in the planning process. This may yield the additional advantage of indicating the scale of production and the variety of local raw materials which can be processed in the industrialisation programme.

In the Tugela Basin this is being effected by three Research Projects:

\section{(i) Plant ecology survey}

The type of plant community found in any area is a reflection of the resultant life-supporting capacity of all the environmental factors over a prolonged period of time. Every major plant community develops by a process known as the plant succession, which begins with the invasion of an area by certain pioneer species which react upon the area in such a way as to make it a more favourable area for plant growth, so that other plants are now able to invade the area. This succession of one community after another takes place until eventually a stage is reached when no further development of this kind is possible, because the 
environmental conditions of climate and soil set a limit to the type of community which the locality can support. Such a community is known as the climax community.

The skilled ecologist can recognize not merely the stage which has been reached in the plant succession but also whether the process is on the upgrade to the climax or whether, as frequently happens when soil erosion is taking place, the whole process is going backwards. He can therefore predict what the states of soil and vegetation will be in the future.

Furthermore, the occurrence of certain types of natural vegetation will indicate the varieties of agricultural produce which can safely be produced, but the purpose of the project is not merely to map the plant communities but also to account for their occurrence.

With the assistance and advice of Professor A. W. Bayer, Professor of Botany at the University of Natal, the Commission established a Plant Ecology Research Fellowship for the Tugela Basin at the University in 1954. The Research Fellow completed his survey ten years later and his report which includes a section setting out the practical application of the information collected to problems of land utilization, will be published shortly.

\section{(ii) Soil Survey}

As the work on the Plant Ecology Survey progressed it became apparent that it was desirable to have a fairly detailed knowledge of the soils of this region. After consulting Professor E. R. Orchard, Professor of Agricultural Chemistry at the University, the Commission decided in 1957 to undertake a soil survey of the Tugela Basin, and in view of the great interest of the Department of Agriculture, suggested a joint sponsorship of the project by the two authorities. A division of responsibilities was therefore agreed upon and as a result a reconnaissance soils map to the scale $1 / 100,000$ is being compiled in conjunction with the Soil Survey Section of the International Training Centre for Aerial Survey at Delft in the Netherlands, who have seconded Dr J. J. van der Eyk of the International Training Centre to the Department. The project will be completed within the next few weeks.

The survey is based on the interpretation of aerial photo mosaics augmented by field observation and laboratory 
analysis.

(iii) Agro-economic research

The report on the soil types and the mapping of their occurrence will give a lead to the systems of farm management and the degrees of intensification which can safely be practised in different parts of the region. When, however, the information on soils is correlated with the plant ecology report and map which records the resultant effect of the other environmental factors, it will be possible to assess the agricultural potentialities of the Tugela Basin. The Commission has been fortunate enough to secure the services of Professor John Phillips, a distinguished ecologist, to undertake this important task.

\section{Forestry}

In 1964 the Commission retained Mr C. S. Hubbard, a forestry consultant to report upon the possibility of an integrated forest industry in the Tugela Basin. The consultant's report mapped the areas in which it is physically possible to grow trees and studied the economics of conducting saw mills and pulp mills in the Basin. One interesting conclusion was that it would be economically and silviculturally feasible to plant 100,000 acres of trees in the Qudeni-Nkandla Bantu area to supply a local pulp mill. It is estimated that such a project would afford employment to 2,000 Bantu labourers during the first 12 years, increasing to 3,000 thereafter.

\section{Water resources}

(i) Quantity

The enormous water resources of the Tugela Basin are well known, but their exact magnitude could only be determined by observations at gauging weirs conducted over a series of years. After a careful survey of the situation the Commission made representations to the Department of Water Affairs, as a result of which 25 additional gauging weirs have been built by the Department in Natal, and the Commission retains observers to record the flows. Expert estimates have also been made of the sustained flows which could be secured at all key points in the region by means of storage. 
(ii) Quality

For industrial and irrigation purposes, the quality as well as the quantity of water is important.

Particularly if intermittent pollution occurs, the chemical composition of the water in a stream will vary from time to time and from place to place, so that two chemists taking samples from the same river are liable to arrive at quite different analytical results. The effects of pollution are, however, more lastingly expressed in the composition of the biological life of the streams, and since the fauna cannot change appreciably from day to day, the degree and duration of pollution can often best be measured in the first instance by biological means and correlated subsequently with chemical observations.

The Commission, therefore, in association with the C.S. I.R., sponsored a biological and chemical analysis of the waters of the rivers of the Tugela Basin, a project which was begun in 1953. The rivers have been classified into zones or regions where the biological species will ordinarily be expected to be similar, and a careful count has been made of the species present at different seasons of the year. In the future, any unexpected deviation can be examined for suspected contamination. Some 600 species have been identified in the laboratory. ${ }^{2}$ ) More recently a bacteriological survey of the rivers has been begun.

The great value of having an accurate record of the species in the rivers of the Tugela Basin at this early stage in its industrialization needs no emphasis. It is understood that the river survey of the Tugela Basin is more advanced than any comparable survey in the United Kingdom where available scientific resources have had to be diverted to deal with ad hoc problems associated with the gross and longstanding pollution of rivers.

(ii) Silt survey

Variations in quantities of silt carried in suspension are greater and more frequent than biological and chemical changes. This fact combined with quick fluctuations in river flow makes frequent silt sampling imperative, and during floods, sampling must be carried out at two-hour intervals day and night. This is not easy to arrange and as a result silt stations have only been established at 3 points on the Tugela 
River and 4 points on the Buffalo River. Nevertheless these stations have produced some very remarkable findings and in conjunction with the soil survey provide valuable information on the scale and source of soil erosion.

The technique evolved is to filter a known volume of the mixed sample through a weighed filter paper. The residual silt and the paper are then oven-dried and weighed and the net silt weight contained in the sample is correlated with the recorded river flow at the time the sample was taken. Some 15,000 samples have been taken and processed. In the season 1957/58 the silt load at Tugela Mouth was 12 million tons.

\section{(iv) Marine disposal of effluents}

The influence which the sea is likely to exert on future industrial location in South Africa is not commonly realized. Many industries are confronted with formidable problems when required to render their effluents sufficiently innocuous as to be capable of discharge into streams and rivers. Even if the technical problems can readily be solved, extensive areas of land, large volumes of water and considerable expense may be involved. With the increasing tightness of the water position in the interior, it is likely to become progressively more difficult in these areas to obtain the dilution necessary to purify trade wastes by land treatment, so that factories with major effluent problems will probably have to be sited at the coast. For this purpose the Natal and Zululand coasts are particularly important, being the closest to the Witwatersrand market and the port of Durban.

It is therefore important that the problems of disposal in the sea should be carefully studied so that the most favourable discharge points can be located and the techniques and precautions necessary to avoid nuisance determined.

Long-term studies for this purpose have therefore been sponsored by the Town and Regional Planning Commission and a number of institutes of the Council for Scientific and Industrial Research with the assistance of local authorities and industrialists. There is reason to hope that the findings of this research will enable the coast line to be protected from nuisance. 


\section{Industrial development}

One of the major objects of the regional survey is to determine the suitability of the region for comprehensive industrial development.

The question of whether factories will come to any undeveloped region is most frequently decided by economic factors which have nothing to do with the merits of individual sites and their facilities, but are concerned with the operation of those broad location factors which determine the pattern of industrial development throughout the country as a whole. Most industries are tied to a greater or lesser extent, either to a market or a source of raw material or labour supply, and no provision of physical utilities outside its economic orbit will attract the industry away from its economic location. A review of the operation of national location factors has confirmed that the region is favourably situated in this respect.

Certain basic influences are, however, imperfectly understood and two research fellowships in the field of economics, augmented by other investigations, were conducted to elucidate these questions.

\section{(i) Tugela Basin industrialization research}

This fellowship was established in 1958 to determine the types of secondary industry best suited for establishment in various parts of the Tugela Basin. This investigation examined the economic practicability of establishing the various classifications of industry at sites within the Tugela Basin having regard to sources of raw materials, the positions of markets, availability of labour, and other relevant factors.

\section{(ii) Railway rating}

Where different rates are charged by the railway for conveying bulk raw materials as compared with the finished or partly finished product, the most economical location for the producing factory may be determined by the relative difference between the charges for the two types of freight. The effect of this on industrial location is not difficult to imagine. A Railway Rating Research Fellowship was therefore established to study the precise effect on the development of Natal of the present railway rating system, and the report of the Research Fellow will be published shortly. 
As a result of the encouraging view of the region's industrial prospects which was justified by the overall economic survey, it became necessary to determine the most suitable sites for comprehensive industrial production centres. In order to achieve this by a process of objective analysis unaffected by the enthusiasm or apathy of local sentiment, all the land in the Tugela Basin has been subjected to a series of analytical sieves in which the most likely industrial sites were quickly seperated from less promising areas.

By this method, in the search for industrial development centres the 11,200 square miles of the Tugela Basin has been narrowed down to 22 square miles. The most vital sites and their approach siding routes can therefore be protected from incongruent development and the general planning of urban development in the vicinity can be undertaken.

(iv) Urban and rural water demands

From the information on the extent of irrigable and industrial land in the various catchments, a rough estimate has been made of the quantities of water likely to be required for each purpose, in order to ascertain whether a conflict is likely to occur between agriculture and industry for the available water.

A comprehensive illustrated report on the regional survey has been published. ${ }^{3}$ )

\section{Hydro-electric power}

The comprehensive information about the region stimulated first of all $\mathrm{Mr} \mathrm{C}$. E. R. Langford, a Johannesburg consulting electrical engineer, and later $\mathrm{Dr} \mathrm{H}$. Olivier and Professor D. C. Midgley to examine the hydro-electric potentialities of the Tugela River, and these have since been examined by the Electricity Supply Commission. The terrain above Colenso is favourable to the construction of storage dams which can smooth out the flow of the river, while the rapid fall of the river in the rugged country below Colenso is suitable for the harnessing of the river by turbines which can be used to generate electricity. It is maintained that the introduction of hydro power into the Natal electricity system would prove economic in its own right, while the storage dams could be used for industry and maybe irrigation. The regional plan shows how the same water can be used 7 times 
over by successive use at industrial sites and hydro-electric power stations.

\section{Three Rivers Region}

In contrast with the Tugela Basin, which is a virtually undeveloped area, the Three Rivers Region contains the Durban Metropolitan area (population 681,492), as well as the capital city of Pietermaritzburg, and includes 58 per cent of the European population of Natal and nearly 80 per cent of its industry.

The most important river is the Umgeni, on which both Pietermaritzburg and Durban depend to a large extent for water. With the co-operation of all the principal water authorities and water users, the Commission sponsored a joint survey of the resources of the Umgeni River. A technical committee representative of the interested parties has produced an invaluable report setting out the resources of the river, the demands likely to be made upon them and a suggested programme of development. ${ }^{4}$ ) This programme has been accepted by the Central Government, which has already constructed at Midmar the first 130,000 acre feet dam suggested by the Committee. A chemical, biological and silt survey of the Umgeni River has been conducted on the same lines as that described for the Tugela. For this we are greatly indebted to Dr H. J. Schoonbee of Potchefstroom University, who was responsible for the biological studies. No one could have brought greater enthusiasm and devotion to the task, which was completed in record time and with great distinction.

A land use survey of the whole region is under way, and plant ecology and soil surveys have been begun.

In order to deal with urgent problems, investigations along the Natal North Coast and in Greater Durban have been pushed ahead of the general Three Rivers Survey.

\section{Natal North Coast}

The construction of a new National Road along the coast north of Durban has exposed this region to the risk of wholesale sporadic speculative land subdivision. The Natal North Coast Survey ${ }^{5}$ ) is designed to provide a basis for the planned development of the North Coast from a limited number of nuclei. 


\section{Pietermaritzburg-Durban Region}

A land use survey of Greater Durban has been completed, but before a comprehensive long-term regional plan could be evolved, it was felt to be essential to have a more precise knowledge of the economic base of Durban.

Three fellowships were therefore established for this purpose:

The first comprised an historical survey of the growth and structure of industry in Greater Durban, determining the degree of inter-dependence which exists between the various types of industry, and making an assessment of the pattern and scale of future industrial development. ${ }^{6}$ )

The second - of great importance at a port - ascertained the extent to which secondary industry in Greater Durban is dependent on (a) imported and (b) local raw materials and then assessed the influence which these factors have on the location of secondary industry. ${ }^{7}$ )

The third comprised a survey and analysis of the labour resources of Natal in an attempt to forecast whether the probable rate of industrial development is likely to be impeded by a labour shortage or conversely, whether the work opportunities are likely to messure up to population growth..$^{8}$ )

With this fundamental knowledge at is disposal, the Commission felt the stage had been reached when a formal start could be made on the preparation of a regional plan for the area.

In association with the Natural Resources Development Council (now a section of the Department of Planning), and with the co-operation of the principal Government Departments and other bodies, in 1962 the Commission appointed the Pietermaritzburg-Durban Regional Planning Committee to undertake the formulation of a comprehensive development plan for the region. For this purpose the Commission seconded several qualified planners from its staff to work full-time on the regional plan. Although the members of the Committee are appointed in a personal capacity, it will be seen from the Appendix that the membership embraces a vide range of statutory authorities and technical fields.

Much of the terrain is extremely rugged and a relief model was therefore essential to enable the Committee to appreciate readily the implications of any proposals which 
may come under consideration. Separate master moulds were made for the area covered by each 1/50,000 Trigonometrical Survey map sheet, from which any number of fibre-glass relief models could be cast. Any site model can be assembled by bolting the individual map sheet relief models together. Different sets of models can be coloured up to illustrate topography, geology land use, plant ecology, soils, planning proposals etc.

Among the studies which have been instituted is an analysis of past population movements, together with a forecast of future population distribution and a detailed survey showing the present distribution of employment.

With this and other material before it, the Committee is new engaged upon the formulation of a regional development plan.

\section{Natal South Coast}

A Regional Planning Committee for the South Coast south of the Umkomaas River has just been appointed, but at the time of writing has not yet met.

\section{Conclusions}

The foregoing has outlined the technical means which have been adopted to further the advance of regional planning in Natal.

It remains in conclusion to mention some of the guiding principles which have also been followed.

\section{The power of persuasion}

The staff and research fellows of the Town and Regional Planning Commission have at all times enjoyed the fullest help and co-operation from government departments. Indeed, senior government officials serve on many of the Commission's Steering Committees. It would, however, be unrealistic for the Commission, which is a provincial body, to expect government departments to accept its views without question on subjects on which they have unrivalled knowledge and experience. Having examined a regional problem and having by means of a comprehensive report shown how various development factors will react on each other, the Commission 
relies on its powers of persuasion through the Department of Planning, to induce the department to adopt as its departmental policy, the recommendations of the report. If the case is factually documented and logically sound there is likely to be no difficulty in securing the co-operation of the government department.

The influence of a regional planning authority is likely to be directly proportional to the volume of original research which it has sponsored.

\section{Importance of long-term research}

Regional Planning must be based on a thorough knowledge of the factors which are operating. If this knowledge is not available it must be got, and long-term plans cannot be prepared until it is obtained. The emphasis must always be on accuracy and reliability rather than expedition, and for this reason the heat has never been turned on a research worker to skimp his work to comply with some administrative D-day.

Confronted with urgent and weighty decisions, public authorities are prone to believe that at any given ime, the next 18 months or even 6 months are the most critical in the history of a city or a region, and that information not available for decisions made in that period, is of little practical value. As a result, there is an emphasis on the short-term investigation and a feeling that a superficial report is better than no report at all.

It is essential that planners and authorities grappling with day to day problems must be furnished with the best information that can be gathered in the time available, but very often, long-term solutions to long-term problems demand long-term research. There is, therefore, a need for both sorts of investigations, both long- and short-term - but it is vital that the pressure of urgent events shall not prevent research organisations, such as I trust this Institute will be, from pursuing the search for solutions to fundamental problems, however long it takes.

It is not difficult today, to see that in many respects in the 11,200 square mile Tugela Basin, the Planning Commission has a solid bedrock of scientific fact upon which plans can be built up. Knowledge of soils and vegetation enable 
systems of land management to be devised to increase production and conserve the soil. Knowledge of the quality and quantity of water resources enable water purity to be maintained and improved, and ways for meeting the requirements of industry, power generation and irrigation to be devised. The study of industrial location factors and industrial sites enable facts to be placed at the disposal of industrialists to expedite industrial expansion.

The value of all this information is not disputed today, but it is salutary to remember that the plant ecology survey took 10 years, the soil survey 8 years and the rivers research has been going on for 12 years. During most of these periods the incomplete data have been of limited value to the solution of ad hoc problems, but it is clear that the trimming of the research programme to fit short-term aims, would have been fatal to the building up of the comprehensive regional picture.

\section{The role of the planner}

Throughout its life, the Town and Regional Planning Commission has recognised that while policy is the prerogative of the Commission, planning technology is the function of the planner. No decisions are taken without fully documented submissions and recommendations from the professional staff. Just as the initiative in the design of a building must come from the architect - but in accordance with his client's requirements and subject to his approval - so the initiative in the formulation of a regional plan must come from the planner, but in accordance with national policy and the requirements of society as represented by the regional planning authority.

The important function of the regional planning authority is to relate the overall plan to public opinion and the specialised requirements of various Departments of State. It is vital, however, to appreciate that regional planning is too complex a process to be conducted "off the cuff" at a meeting round a table. Each stage in the synthesis of all the complex and sometimes conflicting requirements, must first be undertaken by skilled planners and associated specialists working over a period of months. The product of their labours must then be submitted to the critical analysis of all the interests represented on the Regional Planning Com- 
mittee, where any necessary adjustments and modifications must be introduced into the next step in the planning progress.

It is because the forward momentum of the Plan is dependent on the efforts and energy of the planners, that the national need for more planners is such a vital one.

The planner cannot be a specialist in all the professional skills concerned with regional development, but it has come to be realised that the ability to view the whole pattern of development holistically and objectively and balance the claims of all the components, is a specialised discipline which it is the purpose of this new Insitute to instill into the students. We all wish it Godspeed in its task.

Pietermaritzburg.

E. Thorrington-Smith.

\section{APPENDIX}

Membership of the Pietermaritzburg-Durban Regional Planning Committee

\section{Chairman:}

Mr E. Thorrington-Smith, Director, Town and Regional Planning.

Members:

Mr H. P. Alexander, Manager, Natal Undertaking, E.S.C.O.M.

Mr W. F. Armstrong, Chief Engineer, Department of Water Affairs.

Mr M. C. v. T. Barker, Deputy Chairman, Group Areas Board.

Mr F. H. Barnard, Under-Secretary, Department of Housing.

Mr E. Adler, Chief, Natal Region, Agricultural Technical Services.

Mr. C. G. Hands, City Engineer, Durban.

Mr D. V. Harris, City Engineer, Pietermaritzburg.

Dr D. H. Hooey, Chief Medical Officer, State Department of Health.

Prof. O. P. F. Horwood, William Hudson Professor of Economics, University of Natal.

Mr F. Jackson, Head, Division of Planning and Productivity, South African Railways.

Mr A. Kinmont, Director of Special Works, Durban Corporation.

Mr E. A. H. MacDonald, Chief Engineer, Roads Department, Natal. 
Mr A. E. Noble, Urban Areas Commissioner, Department of Bantu Administration and Development.

Dr R. P. Seymour, Medical Officer, Local Health Commission.

Mr D. G. Tees, Town Clerk, Pinetown.

Mr M. J. van Eyssen, Regional Under-Secretary, Department of Indian Affairs.

Mr C J. Viljoen, Assistant Director, Natural Resources Development Council.

\section{References:}

1. Tugela Basin. A Regional Survey of the Catchment Area of the Tugela River and its Tributaries. E. Thorrington-Smith. Town and Regional Planning Commission, Private Bag 9038, Pietermaritzburg, Natal, South Africa, 1952. R3.50.

2. See Hydrobiological Studies on the Tugela River System, Part I. The Main Tugela River. Article by W. D. Oliff, B.Sc., (Hons.), in Hydrobiologia. The Hague, 10.3.1960.

3. See Towards a Plan for the Tugela Basin. E. Thorrington-Smith. Town and Regional Planning Commission, 1960. R3.00.

4. Water Resources and Water Requirements within the Umgeni River Catchment. Town and Regional Planning Commission, 1961. R125.

5. Natal North Coast Survey. R. A. Pistorius. Town and Regional Planning Commission. R4.00.

6. Industry in Greater Durban, Part I. Mrs M. F. Katzen, M.A. Town and Regional Planning Commission, 1961. R4.90.

7. Industry in Greater Durban, Part II, J. L. McWhirter, B.Sc. Town and Regional Planning Commission, 1959. R2.25.

8. The Population and Labour Resorces of Natal. J. R. Burrows, B.A., (Honns.). Town and Regional Planning Commission, 1961. 